\title{
DEFORMATION AND RECRYSTALLIZATION TEXTURES OF ROLLED AND CHANNEL-DIE COMPRESSED HIGH PURITY COPPER
}

\author{
H. Hammelrath*, J.F. Bulter,Jr. ${ }^{* *}$ H. Hu and K. Lücke* \\ * Institut für Metallkunde und Metallphysik, RWTH Aachen \\ - Department of Materials Science and Engineering, University of \\ Pittsburgh, Pittsburgh, PA 15261, USA
}

\begin{abstract}
Pure copper was deformed in two different ways between $70 \%-95 \%$ and subsequently primary recrystallized. With the help of ODF-analysis the deformation and recrystallization textures for the different deformation degrees were determined. Noticeable differences were observed in both the deformation and recrystallization textures of the strips produced by these two deformation modes. For deformation texture the rolled strip shows stronger $\mathrm{C}$ - and S-, but weaker B-orientation in comparison with channeldie compressed strips. Also the orientation scattering is larger in the rolled strips. For the recrystallized specimen the Cube is stronger and the twin orientation is weaker than in the channel-die compressed strip. These observed differences are all more prominent at higher reductions. The causes of this differences will be discussed.
\end{abstract}

\section{INTRODUCTION}

The rolling deformation has widely been considered equivalent to plain strain compression. By invoking the Taylor theory ${ }^{1}$ qualitative agreement between textures predicted by this theory and experimentally obtained textures already was achieved ${ }^{2}$. The great increased interest in the study of the origin of the Cube texture in fcc metals has induced the use of single and bicrystals with controlled orientations for a systematic study of the problem ${ }^{3}$. To enable a more precisely controlled deformation of these crystals, a channel-die compression device has been employed instead of a laboratory rolling mill. It is known that for the formation of a strong Cube texture upon recrystallization a high degree of reduction, preferable $95 \%$ or higher, is required ${ }^{4}$. It is also known that the formation of the Cube texture is highly sensitive to many other factors, besides the degree of deformation. So it is highly desirable to test the validity of the presumption that rolling deformation is essentially equivalent to plane strain compression, particularly at high strains, by comparing the deformation and recrystallization textu- 
res of the strips processed by these two deformation methods. A preliminary investigation of this problem was carried out already by simply comparing the deformation and recrystallization textures in rolled and channel-die compressed strips of electrolytic copper, using conventional pole figure

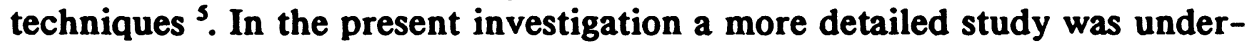
taken, using high purity copper and the ODF techniques.

\section{EXPERIMENTAL PROCEDURE}

High purity copper (99.995\%) was cast under Argon atmosphere in a preheated mold. After machining the ingot to an initial dimension of $50 \times 55 \times 65 \mathrm{~mm}^{3}$, the piece was cold compressed in a $600 t$ forcing machine along the three perpendicular directions and then annealed 1 hour at $400^{\circ} \mathrm{C}$ for recrystallization. Such cycle was repeated three times while the initial shape of the piece was approximately preserved. This led to an almost textureless fine-grained microstructure (mean grain diameter: $-33 \mu \mathrm{m}$ ). This processed piece of copper was cut into two parts: one for rolling and one for corresponding channel-die compression. Five levels of deformation, in the range of $70 \%-95 \%$ reduction were applied. To avoid uncertainties arising from a texture gradient in the specimen, different initial thicknesses of the pieces were used which for the various levels of deformation, all would yield to the same final thickness $(0.9 \mathrm{~mm})$. The width of the rolling pieces was $\approx$ $35 \mathrm{~mm}$. In order to achieve homogeneous deformation by rolling the ratio of contact length to specimen thickness $\ell_{d} / d>1{ }^{6}$ was always observed. For plain strain compression the work piece was cut to fit the $15.88 \mathrm{~mm}$ channel and was wrapped in teflon foil to reduce surface friction during deformation.

For recrystallization the rolled and correspondingly channel-die compressed samples were annealed side-by-side in an oil bath at $171^{\circ} \mathrm{C}$ till recrystallization. The texture was measured on an area of $14 \times 24 \mathrm{~mm}^{2}$ at the centre layer of the specimen. The rolled samples were cut from the middle portion of the strip to minimize the effect of widening on the texture. The $\mathrm{X}$-ray pole figures were measured in the range of $\alpha=5^{\circ}-85^{\circ}$ with the help of a fully automatic texture goniometer ${ }^{7}$ in back reflection mode. From four such incomplete pole figures $(\{111\},\{200\},\{220\},(113\})$ the ODF was calculated after correction and symetrisation using the series expansion method ${ }^{8}$, they are ghost-corrected according to the method of Lücke et al. 9 . Further evaluation of the ODF data by Gauss-model calculation and skeleton-line analysis was carried out 9,10 .

\section{EXPERIMENTAL RESULTS}

The deformation texture of the strips deformed by rolling and by channel-die compression were largely similar, but significant differences were developed with increasing reduction. The ODFs of the $95 \%$ deformed 
specimens are shown in Fig.1. One notices that the orientation scattering in the rolled specimen is somewhat larger than in the channel-die compressed specimen. The differences in the deformation textures show up more clearly by comparing the orientation densitys along the $\boldsymbol{B}$-fibres (Fig.2a and b). One sees immediately that for example, at $95 \%$ reduction the rolled strip has considerable stronger C-(i.e. $\{112\}<111>$ ), and S-(i.e. $\{123\}<634>$ than B-(i.e. $\{011\}<211>$ ) orientation, whereas in the channel-die compressed strip the density of these three components is approximately equal. Moreover, $\mathrm{C}$ - and S-orientation after $95 \%$ rolling are stronger than after channel-die compression, but $B$ is stronger after channel-die compression. The scattering of the Cube orientation around RD is shown in Fig.3a,b. While in rolling the Cube remains at about random level in orientation density with increasing reduction, in channel-die compression it decreases to a level which is barely detectable at $95 \%$ reduction. Parallel to the texture measurements the corresponding microstructure for the various deformation degrees in both series were observed by optical microscopy. One see that there is also a visible difference.

The results of the volume fraction analysis are shown in Fig.4. It can be noted that at high reductions the $\mathrm{C}$ - and $\mathrm{S}$-components are larger in the rolled than in the channel-die compressed specimens, but the B-component in the channel-die compressed specimens is stronger and larger than in the rolled material.

The $\{111\}$ pole figures of the recrystallization textures for the rolled strips are shown in Figs.5 and for the channel-die compressed in Figs.6. It can easily be noted that the Cube texture formed upon recrystallization in the rolled samples is substantially sharper and stronger than in the channeldie compressed specimen. Also, the maximum intensities of the twin orientations (1. and 2. generation) are somewhat lower and the scatter is less extensive in the rolled than in the channel-die compressed specimens.

\section{DISCUSSION}

From the experimental results as described it appears quite certain that there are differences in both the deformation and subsequent recrystallization textures. An obvious difference between the two deformation methods is the mean strain rate which was calculated to be larger by a factor of about 1000 in rolling than in channel-die compression. Since a textural change from copper toward brass orientation take place first by increasing the reduction rate by a factor of about $5000^{11}$, the strip widening in rolling deformation which was found to increase with increasing rolling reduction may have played an important role in causing the textural difference observed. Though the textures showed no detectable differences between specimens cut out from the right and left edge from the central portion of the strip, the difference in material flow would cause a different participation 
a different participation of the main shears (e.g. $\varepsilon_{\mathrm{RN}}, \varepsilon_{\mathrm{TN}}, \varepsilon_{\mathrm{RT}}$ ) between the two deformation methods. Consequently a difference in the deformation texture results. A computer simulation of rolling texture with widening and a channel-die compression texture without widening ${ }^{12}$ showed that the characteristics of the calculated textures are largely in agreement with the experimental observations.

A study of the kinetics of recrystallization of rolled and correspondingly channel-die compressed specimen was already conducted ${ }^{13}$. Both the formation of the Cube texture and the disappearance of the main deformation texture were measured simultaneously. It could be shown that for complete recrystallization the time required for channel-die compressed specimen is longer by a factor of 2 than for rolled specimen. This effect is consistent with the observed orientation spread. It is known that the recrystallization tendency for specimens with very sharp deformation textures is generally weaker than those specimens with less sharp deformation textures and more extensive orientation spreads. The relationships between the observed differences in the recrystallization texture (kinetics) and the different deformation textures could not completely be clarified. So further investigations will be carried out in the future.

\section{LITERATURE}

1 H. Honneff, H. Mecking, Proc. ICOTOM 5, Aachen, (Springerverlag Berlin, 1978) Vol.1, p.265

2 J. Hirsch, K. Lücke, Acta metall., Overview 76, 2863 (1988)

3 G.D. Köhlhoff, B. Krentscher, W. Wang, K. Lücke, Proc. 7th RIS $\emptyset$ Int. Symp. (1986) p.403

4 W.H. Baldwin, Metals Techn., Tech.Pub, 1455 (1942)

5 J.F. Bulter Jr., H. Hu, Mat. Sci. Eng. A111, 95 (1989)

6 H.O. Asbeck, H. Mecking, Met. Sci. Eng. 34, 111 (1978)

7 H. Hirsch, L. Loof, M. Loeck, K. Lücke, Proc. ICOTOM 7, Noordwijkerhout, 1984, S.765

8 H.J. Bunge, Mathematische Methoden der Texturanalyse, AkademieVerlag Berlin, 1969

9 K. Lücke, J. Pospiech, K.H. Virnich, J. Jura, Acta metall. 29, 167 (1981)

10 K. Lücke, J. Pospiech, J. Jura, J. Hirsch, Z. Metallkde. 77, 312 (1986)

11 T. Leffers, Scripta metall. 2, 447 (1968)

12 T. Leffers, RIS $\emptyset$ Nat. Laboratory, Roskilde, Denmark, private communication

13 D. Juul-Jensen, RIS $\emptyset$ Nat. Laboratory, Roskilde, Denmark, not published 
Figure 1
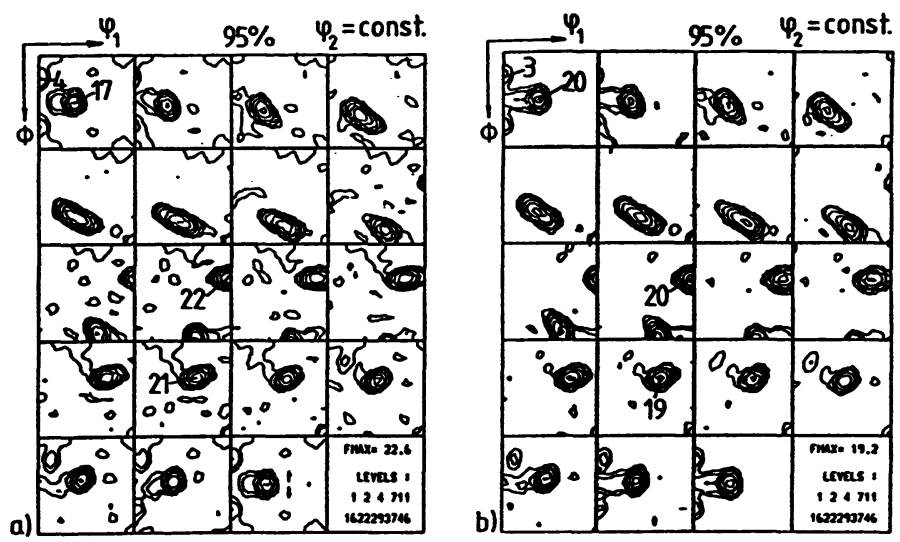
ODFs of the deformed texture (a) rolled, (b) channel-die compressed
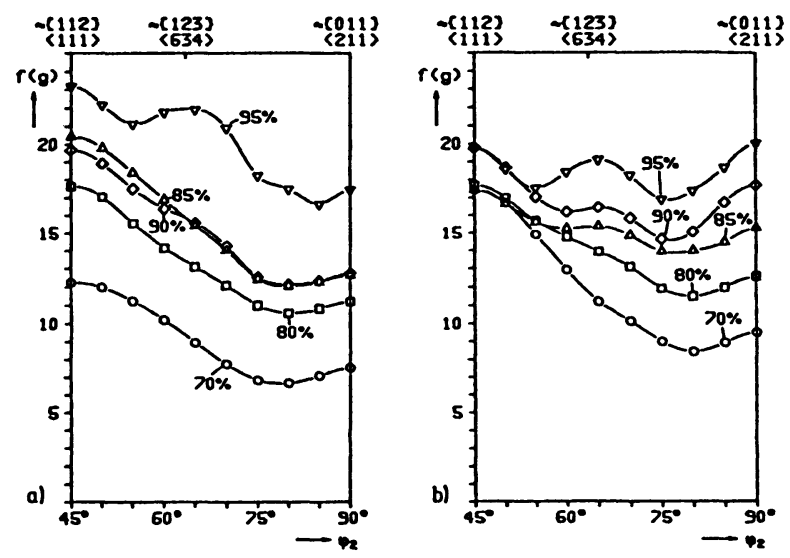

Figure 2 Orientation density $f(g)$ along the $\beta$-fibre after various degrees of deformation

(a) rolled, (b) channel-die compressed
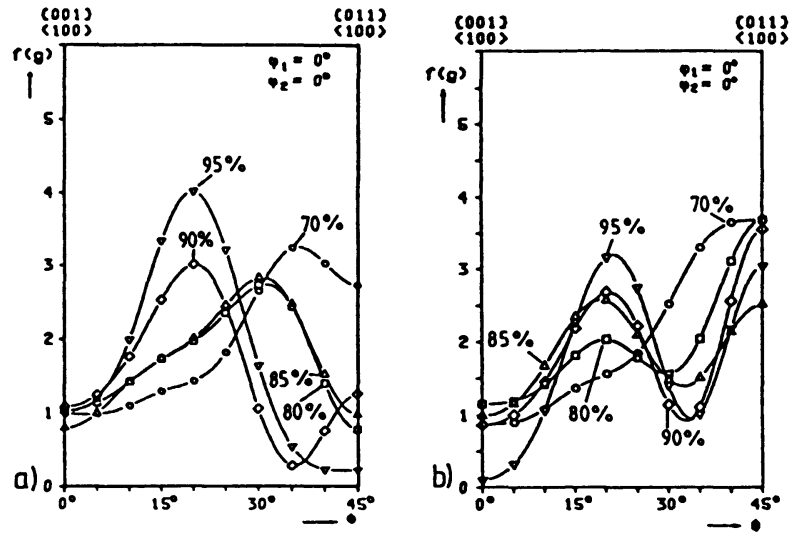

Figure $3 \quad$ Cube scattering around RD after various degrees of deformation. (a) rolled, (b) channel-die compressed of the deformed specimen 

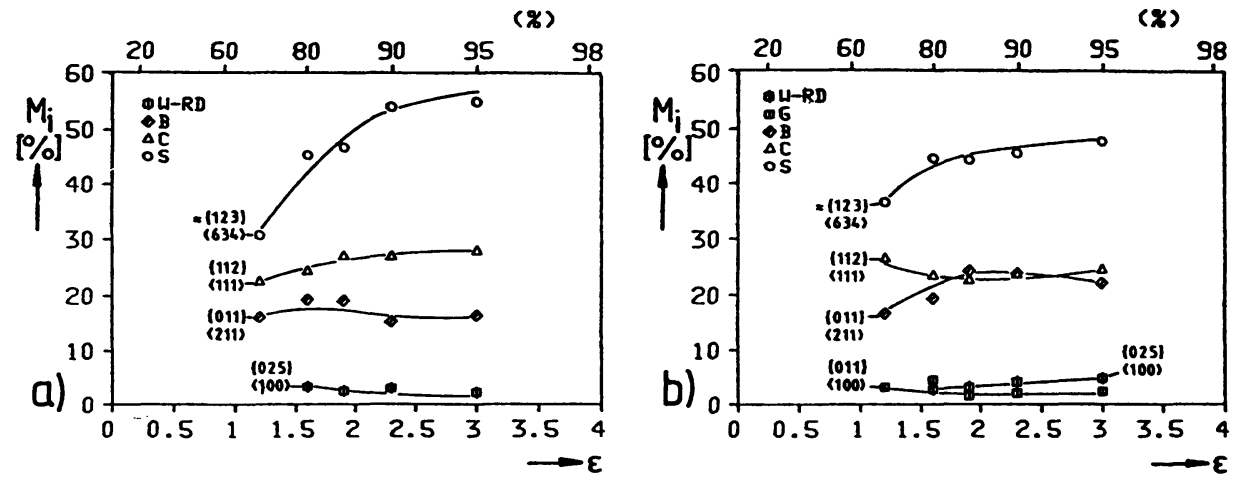

Figure $4 \quad$ Volume fractions $M_{i}$ of the main texture components

(a) rolled, (b) channel-die compressed
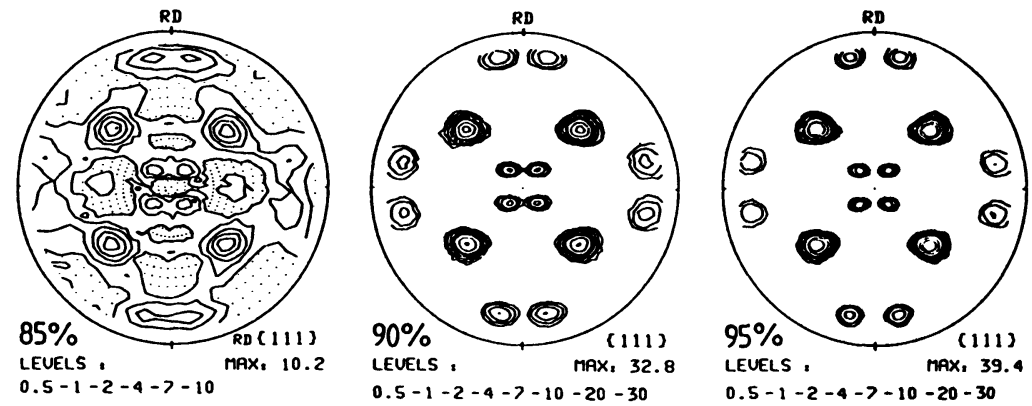

Figure 5

(111\} pole figures as recrystallized for the rolled strips
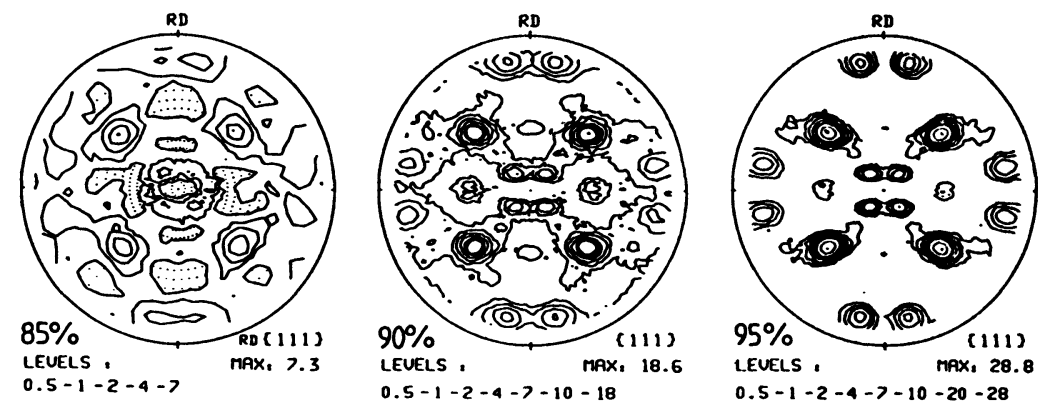

Figure 6 (111) pole figures as recrystallized for the channel-die compressed strips 